\title{
Teaching Teachers To Think: Reflective Journaling As A Strategy To Enhance Students' Understanding And Practice Of Academic Writing
}

Danielle Watson, University of the West Indies, St Augustine, West Indies

\begin{abstract}
The value of reflective journaling as an effective strategy to enhance learning has been explored by several writers. Many see it as a way of approaching learning to enhance the understanding of factors influencing or hindering the learning process and the development of meaning through critical thinking skills. The underlying purpose of the study is to explore the possibility of introducing the reflective journal into the teaching of academic writing as a strategy to improve students' understanding of the different expository methods employed as part of the writing process.
\end{abstract}

Keywords: Reflection; Journaling; Reflective journaling

\section{INTRODUCTION}

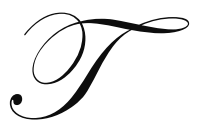

he primary focus of academic writing at the tertiary level is to prepare students to present high quality written works throughout their academic careers. Students are introduced to various expository methods through blended learning strategies. While the methods of teaching have been modified in keeping with changing interdisciplinary trends, the success rate of students has shown little improvements. Bachelor of Education (BEd.) students continue to record higher failure rates within the area of academic writing as opposed to their discipline related courses. A preliminary review of past data also reveals a minimum of two attempts before academic writing is successfully completed. The continued failure of these students demonstrates the need to devise a strategy aimed at addressing the problem they experience with the course of study/instruction.

The study explores the validity of introducing the reflective journal into the teaching of academic writing as a strategy to improve students' understanding of the different expository methods employed as part of the writing process. It proposes to examine the learning outcome of incorporating a series of structured journal writing activities to help students grasp and articulate taught concepts, with the aim of providing actionable direction for reflective journaling as a teaching/learning tool in the area of academic writing.

\section{REFLECTIVE JOURNALING: A BRIEF REVIEW}

Reflective journaling is introduced to BEd. students as an essential part of teacher education. It is acknowledged and promoted as a dominant paradigm in teacher education throughout their programme of study. Ho and Richards (1993) highlight the need for the incorporation of reflective practice into the teaching of English to student teachers. The notion that journal writing presents an opportunity for teachers to use the writing process to describe and explore their own practices can be incorporated into the teaching of classification as an expository method in that it provides a forum to track development in the writing process as it applies to the understanding of expository methods. The goal of reflective action in this manner is to allow the students the opportunity to identify their conceptions and allow them to take more responsibility for their own learning. 
BEd. students are perceived as professionals within their field trained in the area of reflection. They are trained to use reflection primarily for questioning and application. For Liuoliene and Metiveniene (2009), reflective journals focus on ongoing issues with the sole intention of learning from the writing process of acquired findings. As such, the reflective journal is not merely a log or diary of events; instead it focuses on specific topics that lead to further understanding and conceptualization. Not only does journal writing provide an intellectual forum through which thoughts can be assessed, it also accentuates favourable conditions for learning through the encouragement of reflection. This type of journaling allows learners to become active participants in the learning process through active involvement and personal ownership of ideas, thus improving the quality of learning. Learners are allowed to develop problem solving skills which facilitate the exploration of self constructs of meaning.

The incorporation of reflective journaling is perceived as a vital tool to enhance students' understanding of taught concepts. According to Finkle (2000), one of the most effective means for reflecting on experience is writing. Through the documentation of the processes involved in the learning of academic writing, student teachers are provided with a forum to review the factors that hinder/assist the learning process. Richards and Charles (1994) view the reflective journal as serving two primary purposes, namely; the documentation of events and ideas for later reflection and as a process of triggering insight about teaching/learning through self discovery. Topical issues explored range from classroom experiences leading to personal observation and future analysis. Reflective journals allow the writer to note experiences, reflect on these experiences for the purpose of analysis and reassessment as well as to share insight with other learners.

Reflection involves logical problem solving processes, emotion, intuition and passion as a set of problem solving techniques to be employed by student teachers (Green, 1986). These processes require a specialized form of thinking. Grimmett and Erickson (1988) see reflection as a state of being stemming from doubt and perplexity felt in a directly experienced situation that leads to purposeful inquiry and problem resolution. This aligns with the aim of the research in that it seeks to investigate the usefulness of the incorporation of reflective journaling in academic writing as "inferences drawn from the observed phenomena of past experience are tested as the basis for future action" (Grimmett and Erickson, 1988). Such reflective action causes students to interrogate what was not previously done to prevent failure, thus resulting in meaningful learning experiences. Central to the process is the paradox that one cannot know without acting and one cannot act without knowing.

\section{RESEARCH QUESTION}

The major questions that guided the study are as follows:

1. Can the incorporation of reflective journaling in the academic writing classroom improve students' understanding of key concepts?

2. What is the nature of journaling as experienced by the students?

3. How does student journaling contribute to improving their knowledge?

4. Can the processes involved in journaling be identified and used in other circumstances?

5. To what extent are the processes involved in journaling utilized in the conceptualization of academic writing concepts.

For the purpose of the study, reflective journaling is viewed as a strategy to ensure meaningful learning and application of knowledge within a teaching/learning context. It is primarily treated as a tool to assist learners in connecting with knowledge through the questioning of instructional/learning practices geared towards the formulation of meaning.

\section{METHODOLOGY}

\section{The Focus Group And Research Design}

Twenty five students were selected for the study to be conducted during the mid-semester programme. The target group comprised first and second year Bachelor of Education (BEd.) students repeating the academic writing course. These students generally ranged from ages $30-45$. All students within the sample group previously failed 
academic writing. Sixteen of the students failed the course once, five students failed twice, three students failed on three separate occasions and two failed to write the final exam without valid justification resulting in failure based on absence. They were broken into two groups based on personal schedules and preferences.

The research was conducted over a six week period where students were required to produce structured journals at specified times based on different teaching and learning activities centered around a specified expository method. During the first week of the study, students were informed of the nature of the study and its feasibility. They were also informed that their journal entries and written works would be used as a core component of my ongoing research. Twenty students agreed to participate anonymously while, five of the selected sample group declined to participate. The remaining students were asked to voice any concerns and to state their views on being asked to participate in such an activity.

\section{Instructional Component}

The academic writing course was delivered using blended learning strategies. Students were required to attend two weekly two hour lectures and one weekly two hour tutorial session. During the lecture sessions, students were introduced to the various expository methods used in academic writing. This was done via power point presentations coupled with interactive sessions between taught concepts. Summarized lecture notes as well as video presentations were made available to student online via myelearning.

The tutorial sessions facilitated the application of thought concepts. In this forum, students engaged in exercises, both group and individual, to demonstrate their understanding of what was taught during the lectures. Structured activities were conducted and in some instances, immediate group feedback was provided. On completion of the scheduled tutorial activities, students were provided with individual feedback and advised to review their work based on the feedback received. Further practice activities were provided on myelearning where students were able to access feedback immediately after completion of the exercises. The exercises were designed to encourage students to relate taught concepts to real life experiences. During the tutorial sessions, students were used as facilitators in the form of group leaders, which encouraged a certain degree of ownership of the learning experience and decreased dependence on the instructor. These group leaders were responsible for deciding on the approach to be used to answer the questions and to present ideas to other groups or as seen in some instances, select persons to present group findings. For instance, groups would be given a topic and required to decide amongst themselves the expository method to be used and justification of the method selected.

The research accepts that the success of the study is dependent on the participation of students and the production of required work. Conducting the study during the mid year programme also ensures a manageable sample size that allows for the selection and isolation of the required sample group which may not have been possible during the other semesters where student population of the course is considerably larger. Employing reflective journaling strategies in other academic writing courses with larger populations may have varying issues not provided for within the parameters of this study.

\section{Data Collection: Introducing Reflective Journaling}

The processes of reflective journaling allow student teachers to learn from their writing. The interpretation and framing of experiences through the repertoires of instruction, knowledge, tutorial interaction, and practices allow for the formation of what Schon (1983) refers to as appreciative systems. The puzzle or problem presented during the plenary and tutorial, and the actual journal writing processes describe any instance in which the student assumes a gap between teaching and learning. It is at this point that students identify possible areas for improvement in their writing. The journaling activity comprised identifying questions and key elements of a matter that emerged as significant, then taking one's thoughts into written dialogue with self and others.

Reflective journaling was introduced in the second week of the study and specific guidelines were given as to when the entries should be written as well as general guidelines concerning the content of the entries. Billings and Kowalski (2006) express the need for journal entries to have a specified purpose linked to the learning outcome or competencies to be achieved. The reflective paradigm identified by Liston and Zeichner (1991) informed the 
number of reflective journal entries required to gather necessary information for the research. Students were required to produce five entries as follows:

Table 1: Summary of journal entries outlining the number, time and purpose of entries

\begin{tabular}{|c|l|l|}
\hline Entry & \multicolumn{1}{|c|}{ Time } & \multicolumn{1}{|c|}{ Purpose } \\
\hline$\# 1$ & $\begin{array}{l}\text { Before actual engagement with } \\
\text { content/expository method }\end{array}$ & $\begin{array}{l}\text { Students were required to write: } \\
\text { What they think they know about the method } \\
\text { What it entails } \\
\text { Why it is used }\end{array}$ \\
\hline$\# 2$ & After attending the plenary session & $\begin{array}{l}\text { Students were required to articulate how what was taught about the } \\
\text { expository method differed to what they knew. }\end{array}$ \\
\hline$\# 3$ & $\begin{array}{l}\text { After written application of what was } \\
\text { learnt }\end{array}$ & $\begin{array}{l}\text { Students were required to articulate beliefs on the application process } \\
\text { Comment on the application of theory to practice as it relates to the } \\
\text { method. }\end{array}$ \\
\hline$\# 4$ & $\begin{array}{l}\text { After feedback is received from the } \\
\text { instructor }\end{array}$ & $\begin{array}{l}\text { Students were required to articulate the extent to which what they } \\
\text { thought they knew was captured in their application } \\
\text { \& }\end{array}$ \\
& Final scheduled meeting & $\begin{array}{l}\text { Stade what could have been done to improve their writing. } \\
\text { journals }\end{array}$ \\
\hline S5 & \begin{tabular}{l} 
Indicate the usefulness and/or shortcomings of reflective journal usage. \\
\hline
\end{tabular}
\end{tabular}

\section{Interviews}

Interviews were conducted on the completion of the journaling activities. These primarily served as a tool to gather student comments on the journaling process. Semi structured questions were designed to get feedback on the extent to which material was assimilated in journal writing and the extent to which assimilation of journal content was reflected in practical engagement. Both group and individual interviews were conducted. Group consultations were done to facilitate the team component of the course while also providing students the opportunity to hear the views of their peers. Individual interviews were conducted to cater to the needs of students that were less vocal and expressed difficulty voicing their opinions publicly.

\section{Data Analysis Methods}

Because of the small sample group, basic descriptive content analysis was used as well as some elements of logical analysis. Clear objectives were outlined for each journal entry to assess students' understanding of subject matter explored focusing on the expository method, Classification. Content analysis techniques were used to identify key phrases and concepts that demonstrate an understanding of the method as well as students' ability to integrate and successfully apply concepts to differing contexts. Student journals were analyzed and words distilled into fewer content related categories. In so doing, the information relevant to the aim of the study could be extracted. The data gathered was analyzed to reveal what happens during the conceptualization of content and the processes between the receiving of data and the written application of taught processes. The journal entries were grouped to determine the relationship between students understanding and application. In some instances, scales were devised based on the interpretation of student reactions. Because content analysis is less standardized, there are no simple guidelines for data analysis or to judge variations most appropriate to the research. This demanded an extended amount of time for interrogation of data which was somewhat hindered by the duration of the mid semester programme. 


\section{FINDINGS}

\section{Entry \# 1}

The first entry examined students' prior knowledge of the expository method. Reflective journals presented lacked dept and demonstrated little understanding of the expository method. The entries were ranked based on three categories as: surface, off focus and no previous knowledge on subject matter. Where dictionary definitions were given or synonyms were used to explain students understanding of Classification, the responses were deemed surface. These included responses such as "classification involves forming classes" or "classification is the categorizing of information". Where the journal entries provided erroneous information, they were deemed off focus. Such entries included the use of words such as 'steps', 'definition' and 'parts' to explain classification. This also included entries that were not applicable to the expository method. Some students expressed that they had no knowledge of what classification as an expository method entailed and the concept was totally unfamiliar to them. These students were ranked as having no previous knowledge.

Table 2. Prior knowledge of expository method

\begin{tabular}{|l|c|}
\hline \multicolumn{1}{|c|}{ Responses } & No. of Students \\
\hline Surface & 13 \\
\hline Off focus & 4 \\
\hline No previous knowledge & 3 \\
\hline
\end{tabular}

\section{Entry \#2}

The second entry focused on shifts in student knowledge or in some cases expression of students understanding of new concepts. Based on the responses, it was inferred that students had gaps in their knowledge which prevented a grasp of key concepts. The entries reflected a general shift towards an understanding of the method. Students' responses were informed and focused demonstrating an understanding of the method, its uses and its key characteristics.

Table 3. Shift in knowledge of expository method

\begin{tabular}{|c|c|c|}
\hline Understanding of the Method & Number of Students & Sample Comments \\
\hline $\begin{array}{l}\text { Classification as an expository method used to } \\
\text { group and discuss items of a related nature. }\end{array}$ & 然 & $\begin{array}{l}\text { - Classification deals with the grouping of } \\
\text { similar items } \\
\text { The method looks at forming classes based on } \\
\text { the identification of like characteristics } \\
\text { - It helps to organize material based on the } \\
\text { identification of similarities and differences } \\
\text { Where the topic has a plural subject, } \\
\text { classification is used } \\
\text { Where several items are identified as } \\
\text { important, I classify them. }\end{array}$ \\
\hline $\begin{array}{l}\text { Classification requires the identification of an } \\
\text { underlying principle }\end{array}$ & 20 & 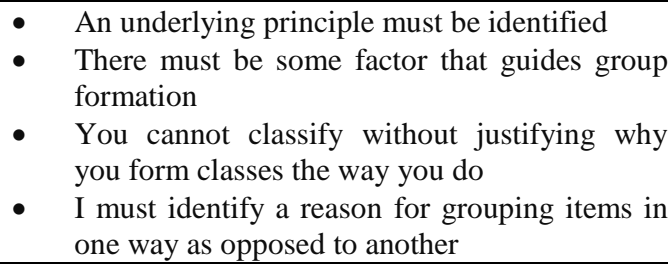 \\
\hline $\begin{array}{l}\text { Groups are formed to include all members of the } \\
\text { various classes as determined by the principle } \\
\text { identified }\end{array}$ & 20 & $\begin{array}{l}\text { - There must be members for it to be considered } \\
\text { a group } \\
\text { - My groups must not overlap } \\
\text { - Where my groups overlap, something is wrong } \\
\text { with my underlying principle }\end{array}$ \\
\hline
\end{tabular}


Several of the strategies identified by Good (2002) were reflected through student responses which required questioning and a degree of comparison. All students demonstrated a shift in their conceptualization of when the method is used and how it is used.

\section{Entry \#3}

Entry three was written on completion of an activity which required the application of what was understood. Students were presented with a topic and required to apply the method as demonstrated in the example presented during their lecture. Their level of understanding was assessed using they key areas necessary for classification. Where students did not attempt the key area identified, the 'no attempt' indicator was used. Where students demonstrated an awareness of the need for the key area but produced erroneous information, they were ranked as 'poor'. Satisfactory was used where the key concept was applied with gaps in students' understanding and 'good' was used to rank well articulated samples.

Table 4. Application of learnt concepts

\begin{tabular}{|l|c|c|c|c|}
\hline \multicolumn{1}{|c|}{ Key concepts for classification } & No Attempt & Poor & Satisfactory & Good \\
\hline Identification of underlying principle & 4 & 2 & 11 & 3 \\
\hline Forming groups/classes & 0 & 0 & 0 & 20 \\
\hline Identifying members & 0 & 3 & 16 & 1 \\
\hline Explaining relationship of group members & 8 & 12 & 0 & 0 \\
\hline
\end{tabular}

This journal entry marked a general shift in students' perceptions as they acknowledged the marked variance in "knowing and doing". The quality of their learning experience was poorly reflected in their performance. Some of their comments in their journal entries were as follows:

"I understand what is required but I have a hard time doing it."

"I know what classification involves but applying it to the topic is harder than I thought."

"If I have to tell you what to do, I can but to write is difficult."

"My problem is coming up with the underlying principle."

These results indicated that the relationship between perception of knowing and actual application is not automatic. The ability to register the required level of transference affects the quality of the learning experience.

\section{Entry \#4}

After feedback was given, $80 \%$ of students admitted a divide between what they thought they knew and what was actually known while $20 \%$ expressed satisfaction with their performance. All students agreed that there was a need for a greater focus on practice and application of taught concepts as opposed to the time spent learning the key concepts. They also agreed that opportunities to incorporate/apply learnt concepts during lectures should be integrated.

\section{Entry \#5}

To analyze students' thoughts on the journaling process, their comments were interpreted and broad categories identified to capture all responses. These categories were devised based on the identified usefulness/shortcomings of the journaling activities. 
Table 5. Student responses to the usefulness/shortcomings of reflective journaling

\begin{tabular}{|c|c|c|}
\hline $\begin{array}{c}\text { Purpose of Journals } \\
\end{array}$ & No. of Students & Comments \\
\hline Aid to understanding expository methods & 19 & $\begin{array}{l}\text { - It helps me think about the method } \\
\text { - It forces me to look beyond what I think I know }\end{array}$ \\
\hline Prompt for note taking & 11 & $\begin{array}{l}\text { - In order to answer the questions for my entries, I have } \\
\text { to make sure I get the required info } \\
\text { My journals help me identify important areas which } \\
\text { means less time spent trying to write everything said }\end{array}$ \\
\hline Academic writing practice & 4 & $\begin{array}{l}\text { - I am forced to write and look at what I write which } \\
\text { helps me look at my writing } \\
\text { What is required of me for journal writing is different to } \\
\text { what I have to do in academic writing }\end{array}$ \\
\hline An instrument for review & 7 & $\begin{array}{l}\text { - } \quad \text { I can look at my journal to track my learning } \\
\text { - } \quad \text { Reading my journal entry paints a picture of how I see } \\
\text { the method in relation to what it is } \\
\text { - } \quad \text { I write down what I don't understand and get clarity }\end{array}$ \\
\hline Increases student responsibility & 5 & $\begin{array}{l}\text { - Journaling forces me to take responsibility for my } \\
\text { learning } \\
\text { - I now have to think about what I write, why I write and } \\
\text { what I should have done differently }\end{array}$ \\
\hline
\end{tabular}

\section{DISCUSSION}

While much of the research points to the overall usefulness of incorporating journaling as a teaching/learning tool within academic writing, the results of the study indicated a need for students to be given more opportunities to actively participate in the learning process through practice exercises. The results of the study indicated a need for the fostering of the relationship between knowledge and application of taught processes. The merit of reflective journaling as an in-class learning activity to stimulate learners to link concepts with practice application is evidenced in the study. The journals provided a forum for students to explore how teaching was articulated and the extent to which feedback enhanced the quality of the learning experience.

\section{CONCLUSION}

The results of the study support other research into the benefits of reflective journaling. The data indicated an overall improvement in students' conceptualization of the expository method. Producing reflective journals require students to go beyond the surface levels of thinking to deep levels of cognition required to grasp expository methods. The study perceives that reflective journals can be incorporated to help students identify key concepts and activate metacognitive strategies to improve their understanding of academic writing concepts. The journaling activity provided students with a structured way to internalize taught concepts through the provision of documented data for problem solving and further conceptualization of expository methods. Students were able to document breakthroughs, acknowledge strengths and weaknesses in their conceptualization, develop strategies and counter strategies for use, recognize possible areas to be clarified and create connections between practice, content and context. It further allowed for students to attend to features of the learning experience that were previously ignored and assign new significance to previously identified areas.

In keeping with the postulation of Boud (2001), the reflective journals "reveal what their writers have learned, examine how writers have learned to express themselves in journals, or find out how journals can help other people learn" ( $p$ 10). The study highlights the usefulness of reflective journaling, while providing a framework to recapture experiences, mull over and evaluate them. Students were encouraged to recast learning experiences in light of clarifying questions, reconsidering the assumptions on which previous understandings of the situation were based and beginning to rethink the range of possible responses. It promotes thorough understanding of a situation, clearly identifying goals, viewing and assessing possible options and thinking before acting (Nicholls 2001). 


\section{AUTHOR INFORMATION}

Danielle Watson is a graduate of the University of the West Indies, with a Bachelors degree in Literatures in English and Linguistics. She is currently reading for a Masters of Higher Education (MHEd) in Tertiary Teaching and Learning and has redesigned an English Language and Communication course for military officials in Trinidad and Tobago as well as remedial programmes to assist students at the tertiary level. Her research interests are in the areas of programme design and evaluation at the tertiary level.

\section{REFERENCES}

1. Billings, D., \& Kowalski, K. (2006). Journaling: A strategy for Developing Reflective Practitioners. The Journal of Continuing Education in Nursing, 37(3), 104-106.

2. Boud, D. (2001). Using Journal Writing to Enhance Reflective Practice. New Directions for Adult and Continuing Education, 90, 9-18.

3. Finkel, D. (2000). Teaching With Your Mouth Shut. Portsmouth: Cook Publishers.

4. Good, J. (2002). Encouraging Reflection in Preservice Teachers through Responsive Journals. The Teacher Educator, 37(4), 254-268.

5. Green, T. (1985). "The Formation of Conscience in an Age of Technology," American Journal of Education 94. November 1985:4.

6. Grimmett P., Erickson G. (1988). Reflection in teacher education. New-York: Teachers College Press.

7. Ho, B. \& Richards, J. (1993). Reflective Thinking Through Teacher Journal Writing: Myths and Realities. PROSPECT, 8(3), 7-24.

8. Liston, D. P., \& Zeichner, K. M. (1991). Teacher Education and the Social Conditions of Schooling. New York: Routledgee.

9. Liuoliene, A. \& Metiuniene, R. (2009). Students' Learning Through Reflective Journaling. Sankalka 17: 32-37.

10. Nicholls, G. (2001) Professional Development in Higher Education. London: Kogan Page Limited.

11. Richards, J., \& Charles L. (1994) Reflective Teaching in Second Language Classrooms. United Kingdom: Cambridge University Press.

12. Schon, D.A (1983). The Reflective Practitioner: How Professionals Think in Action. New York: Basic Books. 